\title{
INSTRUCTIONAL DESIGN IN GAME BASED LEARNING AND APPLICATIONS USED IN EDUCATIONAL SYSTEMS
}

\author{
Damir VUSIĆ, Andrija BERNIK, Robert GEČEK
}

\begin{abstract}
The paper examines literature on the subject of instructional design and game based learning with the aim of identifying its positive effects and impact on users. Special attention was given to learning, encouragement and development of skills acquired through the use of game based learning. Game based learning is considered to be a complex system that requires instructional support geared towards stimulating cognitive processes. Several empirical research papers which provide insight into this field of interest have been chosen. The second set of papers provides confirmation accompanied with an analysis of instructional support as a function of the learning support. Also included were recent works which indicated the need for further research and the heterogeneity of the existing research. Other works complemented the unit and are mutually interconnected by a methodological approach providing insight into the issues that should be investigated in the future.
\end{abstract}

Keywords: cognitive skills; game based learning; higher education; instructional support

\section{INTRODUCTION}

Game Based Learning (GBL) is a system which is being increasingly applied in the educational process, and which has been clearly evinced in a number of scientific papers that have been published over the last decade. In this context, the notion of game based learning has been approached via the cognitive and affective dimension of learning [15] where users can adopt such games for their own cognitive needs and interests and ensure the motivation for learning [11]. Game based learning allows the use of methods which are consistent with the modern theories on effective learning and encourage an active problemoriented, experimentally-interactive and socially mediated access to educational processes in accordance with the current thinking [3, 4]. Hummel et al. [9] suggest that game based learning in institutions of higher education can be seen as a useful tool for developing, implementing, improving and facilitating the student's learning experience. Ucus [22] points out that game based learning can also be used as a tool for educating teachers. All et al. [1] cite recent research in which they clearly point out that there is currently a whole range of heterogeneous research which aims to demonstrate the effectiveness of learning systems that incorporate computer games. The validity and reliability of almost all proposed methods is questionable as such studies are neither sufficiently rigorous nor focused. The rapid development of the Internet and multimedia technology has led to the development of game based learning and has resulted in a significant financial incentive for the development and implementation of game based learning within schools and corporations. From the cognitive point of view on game based learning, it can be easily stated that such games include complex virtual spaces within which a respondent can be easily confused by the amount of information, design and other such elements of the game and, in this way, take a step away from the learning process [24].
This paper will provide an overview of important research regarding the instructional support and empirical evidence of the usefulness of game based learning within educational institutions. Instructional support includes a wide range of techniques and methods that target different cognitive aspects which will be discussed later in this paper. Mayer [13] divides computer game research into three categories: the first approach is based on the added value and explores how computer games promote learning and motivation, the second refers to the cognitive consequences in terms of what people learn from educational games, and the third relates to the comparison of the educational medium where it is examined whether learning with the help of an educational computer game is more effective than the traditional teaching material.

\subsection{Game Based Learning (GBL)}

GBL is a term that can refer to any educational environment which is based on educational elements and content and involves a computer or online game [18]. Prensky [18] states that integration leads to an innovative teaching model which positively affects the comprehension of an educational technology framework. In an ideal educational computer game, the student would learn through simply playing a game within a virtual simulation which involves the interplay of roles and platforms [3]. Ariffin [2] notes that it is important to understand the users of such systems, i.e. the respondents, because the learning performance through computer games is affected by elements such as culture, primary language, ethnicity and an intrinsic motivation to learn new concepts and skills. Ucus [22] links to the idea in his research that proposed the introduction of game based learning at all educational levels, starting at primary school, where it is necessary to educate the teachers as well so that they can understand the pedagogical possibilities of this approach and technology. 
Many researchers have defined or classified computer game characteristics $[7,11,18]$. This work will be limited to a few related characteristics, of which the first is interaction $[18,21]$, specific and exactly defined set of rules and conditions [7], clear objectives conditioned by a creative and cognitive challenge [11] and the feedback derived from monitoring progress through the game by the acquisition of points or changes in the system [18]. The goal of game based learning is not to entertain the respondent, which is merely its added value, but to create a high quality environment for the development of strategic problem solving, communication and other such skills. Through an educational computer game, the user can be focused on two key elements: improving knowledge through goals or improving gaming skills through collecting points. Various research has shown that there is a correlation between the level of intrinsic motivation and educational points where intrinsic motivation refers to the internal desire to learn or solve a problem without requiring entertainment or challenge.

\section{THEORETICAL FRAMEWORK}

Playing computer games is more and more associated with learning and there have been several models developed to identify the effects of education while playing computer games. The authors [7] made a distinction between the learning outcomes based on skills (both technical and motor skills), cognitive outcomes (declared, procedural and strategic knowledge) and affective outcomes (beliefs and attitudes). This final outcome is related to the potential of games that can change a respondent's emotions with the aim of supporting the study. The research of a group of authors [24] proposed a model that contained four learning outcomes based on computer games and cognitive learning outcomes. These have been divided into knowledge, cognitive skills, motor skills, affective learning outcomes and communicational learning outcomes.

From a cognitive perspective, instructional support can be implemented in order to remove the existing limit in human cognitive architecture $[12,17,16]$. All et al. [1] also concluded that a teacher, administrator or responsible person who assists respondents when they are using game based learning should be entirely removed from the system. These functions should only remain as part of the procedural assistance, if required.

Two structures are crucially important in terms of information processing. The first of these is working memory, which has a limited capacity to process information and is often inappropriate for the study of complex, multi-modal and dynamic information.

The second is long-term memory, which theoretically has unlimited capacity. Regarding the cognitive architecture, these theories highlight several important cognitive processes involved in learning. Mayer's cognitive theory of multimedia learning states there are three types of cognitive processing: selection of relevant information with respect to the relevant materials, organizing new information in coherent structures and integration of a structure into existing knowledge [12]. Organization and integration of knowledge are very closely related, which is why cognitive perception in the form of instructional assistance is suggested, as it can be included in the process of learning as follows: the selection of relevant information from teaching materials and active organization of information that is integrated into the existing knowledge in long-term memory [14].

\section{RESEARCH METHODS AND IMPLEMENTATION 3.1 Research 1}

Researchers (Wouters and van Oostendorp) used the Google Scholar Search Engine for their 2012 survey which included the searched terms 'game based learning', 'serious games', 'educational games', 'simulation games', 'virtual environments', and 'muve' (Multi-user virtual environments). As it was necessary to narrow down the received outcomes, the search terms were amended by 'learning', 'instruction' and 'training'. They also studied works and many references that relate to game based learning $[10,15,19,21,25]$. The resulting works dated from 1990 to 2012. The selection of works was made according to the definition of game based learning that was stated earlier by authors in their work. Furthermore, only the works that included research related to the instructional design and clearly defined tests and research samples were taken into account. Of the 197 relevant papers, only 29 meeting the research criteria were included. The research related only to the cognitive domain of learning and these results are listed below. Wouters's [24] classification of cognitive domains shows a visible division between knowledge and cognitive skills. Knowledge refers to a learned trait that is expressed in verbal (i.e. in a written form) or non-verbal (i.e. images) forms. Cognitive skills relate to complex cognitive processes, such as the analysis during problem-solving, where a student applies factual knowledge and rules in the hope of resolving (a new) situation. The situation built during playing the game is the third type of cognitive learning because it can be based on intuitive learning. Instructional support, as mentioned previously, has many divisions which have been respectively listed with regards to cognitive activities.

Regarding the specific instructions that are difficult to classify, authors have decided to categorize them as 'Unknown' (Tab. 1).

Tab. 1 and Tab. 2 have been adopted from the original work of [25] and are listed in this section. For easier understanding, instructional support is also grouped into 10 categories which often occur in game based learning. The categories are classified as follows (Tab. 2): Reflection, Modelling, Advice, Collaboration, Control, Narrative Elements, Feedback and others. 
Table 1 Types of instructional design and their classification in the cognitive process (based on [25])

\begin{tabular}{|c|c|c|}
\hline Type of Support & Description & Cognitive Process \\
\hline Advice & $\begin{array}{l}\text { Systematically created } \\
\text { proposals and } \\
\text { suggestions }\end{array}$ & Selection \\
\hline Adaptation & $\begin{array}{l}\text { Adaptation of a game } \\
\text { to the respondent }\end{array}$ & Selection \\
\hline Assignment & $\begin{array}{l}\text { Encouraging research } \\
\text { of variables }\end{array}$ & Organization/Integration \\
\hline $\begin{array}{l}\text { Background } \\
\text { Information }\end{array}$ & $\begin{array}{l}\text { Domain information } \\
\text { upon request }\end{array}$ & Unknown \\
\hline Signalling & $\begin{array}{l}\text { Signal for directing the } \\
\text { respondent's attention }\end{array}$ & Selection \\
\hline $\begin{array}{l}\text { Collaboration } \\
\text { (Cooperation) }\end{array}$ & $\begin{array}{l}\text { Discussion directed to } \\
\text { the explanation of } \\
\text { implicit knowledge }\end{array}$ & Organization/Integration \\
\hline Selection & $\begin{array}{l}\text { Control over irrelevant } \\
\text { elements of the learning } \\
\text { activity }\end{array}$ & Unknown \\
\hline Contextualisation & $\begin{array}{l}\text { Presenting learning in a } \\
\text { meaningful context }\end{array}$ & Organization/Integration \\
\hline Elaboration & $\begin{array}{l}\text { Additional task directed } \\
\text { to cognitive activities }\end{array}$ & Organization/Integration \\
\hline Feedback & $\begin{array}{l}\text { Information on the } \\
\text { veracity of the answers }\end{array}$ & Selection \\
\hline Announcement & $\begin{array}{l}\text { Announcing future } \\
\text { events }\end{array}$ & Selection \\
\hline Interactivity & $\begin{array}{l}\text { The game responds to } \\
\text { the actions of the } \\
\text { respondent }\end{array}$ & Organization/Integration \\
\hline $\begin{array}{l}\text { 'Just In Time' } \\
\text { Options }\end{array}$ & $\begin{array}{l}\text { Options appearing at } \\
\text { the point when } \\
\text { problems are being } \\
\text { solved }\end{array}$ & Selection \\
\hline Modality & $\begin{array}{l}\text { Using audio channels } \\
\text { for limitations }\end{array}$ & Selection \\
\hline Modelling & $\begin{array}{l}\text { Descriptions of how a } \\
\text { problem has been } \\
\text { solved }\end{array}$ & Selection \\
\hline Narration & $\begin{array}{l}\text { A story which can help } \\
\text { organize } \\
\text { teaching/educational } \\
\text { materials }\end{array}$ & Organization/Integration \\
\hline Pedagogical Agent & $\begin{array}{l}\text { An agent which assists } \\
\text { the respondent through } \\
\text { the game using } \\
\text { instructions }\end{array}$ & Unknown \\
\hline Personalisation & $\begin{array}{l}\text { Adjusting the context } \\
\text { with personal interests }\end{array}$ & Unknown \\
\hline Prior Research & $\begin{array}{l}\text { Obtaining information } \\
\text { of a certain domain in } \\
\text { advance }\end{array}$ & Selection \\
\hline Process/Objectives & $\begin{array}{l}\text { The respondent has } \\
\text { specific objective } \\
\text { which is to obtain a } \\
\text { specific ability }\end{array}$ & Selection \\
\hline Reflection & $\begin{array}{l}\text { Encouragement to start } \\
\text { reflecting on the } \\
\text { answers and on how to } \\
\text { explain them }\end{array}$ & Organization/Integration \\
\hline Surprise Elements & $\begin{array}{l}\text { Unexpected events that } \\
\text { trigger an update of } \\
\text { mental models }\end{array}$ & Organization/Integration \\
\hline Variability & $\begin{array}{l}\text { Showing problems in } \\
\text { different forms }\end{array}$ & Organization/Integration \\
\hline Similar Examples & $\begin{array}{l}\text { Showing how a } \\
\text { problem can be solved }\end{array}$ & Selection \\
\hline
\end{tabular}

Table 2 Descriptions of Instructional Support Groups and how they are Associated with the Types of Instructional Support (based on [25])

\begin{tabular}{|l|l|}
\hline \multicolumn{1}{|c|}{ Instructional Support Group } & \multicolumn{1}{c|}{$\begin{array}{c}\text { Specific Type of } \\
\text { Instructional Support }\end{array}$} \\
\hline $\begin{array}{l}\text { 1. Reflection } \\
\text { Students are encouraged to think about } \\
\text { their answers }\end{array}$ & $\begin{array}{l}\text { Reflection, simple } \\
\text { explanation, elaboration } \\
\text { and task assignment }\end{array}$ \\
\hline $\begin{array}{l}\text { 2. Modelling } \\
\text { An explanation or indication of how to } \\
\text { solve a given problem. An explanation can } \\
\text { be given by a respondent or an expert in the } \\
\text { form of words, pictures or animations }\end{array}$ & $\begin{array}{l}\text { Different types of } \\
\text { approaches to the solution, } \\
\text { modelling and solved } \\
\text { examples }\end{array}$ \\
\hline $\begin{array}{l}\text { 3. Advice } \\
\text { The system generates information to } \\
\text { support and continue the student's learning } \\
\text { (e.g. focusing attention) }\end{array}$ & $\begin{array}{l}\text { All types of advice, either } \\
\text { contextual or adaptive or no } \\
\text { advice at all }\end{array}$ \\
\hline $\begin{array}{l}\text { 4. Collaboration } \\
\text { Working in discussion groups focused on } \\
\text { the explanation of implicit knowledge }\end{array}$ & $\begin{array}{l}\text { Respondents play in pairs, } \\
\text { groups or participate in } \\
\text { group discussion }\end{array}$ \\
\hline $\begin{array}{l}\text { 5. Interactivity } \\
\text { The student makes decisions in the game in } \\
\text { order to solve problems or a specific task }\end{array}$ & $\begin{array}{l}\text { Interactivity, student's } \\
\text { control and decision on the } \\
\text { playing elements }\end{array}$ \\
\hline $\begin{array}{l}\text { 6. Narrative Elements/Storytelling } \\
\text { Storytelling to create a cognitive } \\
\text { framework }\end{array}$ & $\begin{array}{l}\text { Fantasy, rich storytelling, } \\
\text { hints and sudden events }\end{array}$ \\
\hline $\begin{array}{l}\text { 7. Modality } \\
\text { Textual information is displayed aurally }\end{array}$ & Modality \\
\hline $\begin{array}{l}\text { 8. Feedback } \\
\text { Information is displayed regardless of the } \\
\text { accuracy of the action or answer and may } \\
\text { need not) be corrective or explainable }\end{array}$ & Feedback and guidance \\
\hline $\begin{array}{l}\text { 9. Personalisation } \\
\text { Ideas, characters, themes and messages are } \\
\text { displayed in a way that specifically suits } \\
\text { the respondent's interests }\end{array}$ & $\begin{array}{l}\text { Personalisation, } \\
\text { personalised messages }\end{array}$ \\
\hline $\begin{array}{l}\text { 10. Other } \\
\text { Group of instructional support that is } \\
\text { difficult to categorise because of the small } \\
\text { number of comparisons }\end{array}$ & $\begin{array}{l}\text { Focusing on objectives, } \\
\text { background information, } \\
\text { selection and adaptability }\end{array}$ \\
\hline
\end{tabular}

\subsection{Research 2}

The main problem in the design and development of an effective educational computer game is the clear vision of the desired learning result and how to establish an optimum relationship between the desired game properties and desired learning goals [6]. When designing the game and its elements, it is necessary to know in advance which skills and knowledge are targeted.

Games, animations and simulations are interactive and support and contribute to more efficient learning in various ways [23]. For efficient learning it is suggested to use game based learning which offers students active and problemoriented learning, where their own knowledge can be applied to information and real life examples. Also encouraged is the work on practical examples, where a different, critical analysis of the presented data and facts is possibly accompanied by the communication with active users, group or system.

That is why researchers [4] conducted a study in which they wanted to find empirical evidence that shows a positive impact of computer games on the learning outcome. Considering that the subject of research was computer games (Game Based Learning), term 'Game' was a frequently used word by all researchers within the field. The initial query: ('computer games' OR 'video games' OR 
'serious games' OR 'simulation games' OR 'games-based learning' OR MMOG OR MMORPG OR MUD OR 'online games') of the listed researchers was amended by the learning outcome: AND (evaluation OR impacts OR outcomes OR effects OR learning OR education OR skills OR behavior OR attitude OR engagement OR motivation OR affect).

Scientific and professional works found as a result of this search were filtered according to four criteria: included abstract, included empirical evidence relating to computer games, timeframe from 2004 to 2009 and sample aged above 14 , and 129 works relevant for the subject of research were filtered. These works were categorized according to the following domains: Digital - Non-digital Games, Primary Purpose of the Game, Game Genre and Game Platform. Categorization was also conducted according to the outcomes of learning: Behavioral Impact and Learning Outcomes, Intention and General or Specific Impact. This last categorization was based on methods: Design and research, Sample Selection, Sample Details, Group Comparison, Data Collection, Results and Conclusion. In total, 121 or $84 \%$ research studies were quantitative while only 8 or $6 \%$ included quantitative data, $43(36 \%)$ were survey based, $12(10 \%)$ resulted from random check questions and only one study applied the correlation approach. The eight works that included quantitative and methodological results used protocol and perspective analyses. Table 3 has been adopted from Research 2 .

In comparing the genres of games, all eligible works show that simulations are by far the most popular games (43), followed by action games (14), puzzle/mystery/riddle games (11), role-playing games (8), strategic games (6) and adventure games (5). 22 studies researched the impact of general games and 4 focused on online games.

Table 3 Primary Game Purpose Based on All Works (Works with a Higher Quantitative Contribution) (based on [4])

\begin{tabular}{|c|c|c|c|c|}
\hline \multirow{2}{*}{$\begin{array}{c}\text { Research } \\
\text { Design }\end{array}$} & \multicolumn{3}{|c|}{ Purpose of the Game } & \multirow{2}{*}{ Total } \\
\cline { 2 - 4 } & Fun & Education & $\begin{array}{c}\text { Serious } \\
\text { Game }\end{array}$ & \\
\hline $\begin{array}{c}\text { Qualitative } \\
\text { Research }\end{array}$ & $1(0)$ & $4(2)$ & $3(3)$ & $8(5)$ \\
\hline $\begin{array}{c}\text { Correlation } \\
\text { Research }\end{array}$ & $0(0)$ & $1(0)$ & $0(0)$ & $1(0)$ \\
\hline $\begin{array}{c}\text { Quasi- } \\
\text { experimental } \\
\text { Research }\end{array}$ & $32(16)$ & $28(14)$ & $5(4)$ & $65(34)$ \\
\hline $\begin{array}{c}\text { Random } \\
\text { Research }\end{array}$ & $4(4)$ & $6(4)$ & $2(1)$ & $12(9)$ \\
\hline Survey & $31(16)$ & $10(6)$ & $2(0)$ & $43(22)$ \\
\hline Total & $\mathbf{6 8 ( 3 6 )}$ & $\mathbf{4 9 ( 2 6 )}$ & $\mathbf{1 2 ( 8 )}$ & $\mathbf{1 2 9}(\mathbf{7 0})$ \\
\hline
\end{tabular}

The table also shows that $80 \%$ of all games included in the scientific research included simulation games or puzzle/ mystery/ riddle games.

As for the platforms used to play the games, the most popular platform is a PC (73), followed by video consoles (28) and online games (19). Three research studies focused on mobile games and one on a game played in the virtual world. Fun games were distributed evenly across the PC (24) and video consoles (26) and 13 were online. The majority of the games intended for game based learning was designed for a PC (38) and 6 are online. 11 of 12 serious games are available on a PC platform and one game was non-digital.

The main objective of this research was to develop a classification of learning outcomes and impacts of game based learning on motivation and learning. Outcomes received most frequently were affection and motivation (33), followed by the acquisition of knowledge/comprehension of content (32), perception and cognitive skills (20), behavioural changes (13), psychological outcomes (11) and social skills outcomes (11). The method which was most frequently used was the quasi-experiment, followed by surveys, quantitative methods and randomized questionnaires. Most common outcomes of game based learning included the acquisition of knowledge and content comprehension (26), followed by perception and cognitive skills (7). Quite contrary, in fun games, the focus was on the affective and motivational outcomes (26) and several studies showed perception and the cognitive learning outcome (13), and the psychological outcome. As for the serious games, outcomes were divided and there was not a single research that would include the perceptive, cognitive and psychological results of learning.

Simulations and mysteries/riddles are the most widely spread games in game based learning, but other types of games and their contribution to the educational system should also be studied in terms of tasks and activities found in other games. O'Brien [5] has provided an analysis of games that might contribute to the above statement. O'Brien divides games according to the genre into: linear, competitive, strategic, role-plays, with each category being specific and requiring sophisticated actions throughout the game.

Many authors analyzed computer games from a negative point of view, but it has been shown that there is a large number of positive experiences and that game based learning can be used for educational purposes. The stated research has been focused particularly on the positive impact developed through a computer game. It measured what impact fun games, game based learning and serious games have on the respondent and how they could support the learning and development of skills.

The researches [4] discovered many works (7392) that show a high interest for digital games, fun games, game based learning and serious games. A large part of works only assumed how games might affect learning, what the theoretical and design approach to them should be like but, since they did not include the empirical evidence for the application and impacts on the learning outcome, they were not included and considered in detail. 129 works presented empirical evidence of the impact on and outcomes of learning resulting from game based learning. The stated works also pointed to the lacking empirical research. 70 works provided high-quality evidence, although certain elements which were discovered varied from other studies.

A multi-component analysis developed by the authors stated in this research studies the main purpose of the games, their genre, discipline and educational and 
behavioural outcomes of learning and provides a framework to organize and understand the games and their contribution considering the comparison of different variables. Empirical evidence has been identified for all educational and behavioural outcomes of learning, including those for the acquisition of knowledge, perceptive and cognitive, behavioural, affective, motivational, psychological and social. The most frequent learning outcome commonly studied through game based learning was the acquisition of knowledge and content comprehension. Affective and motivational outcomes were studied through fun games.

\section{LEARNING OUTCOMES AND AN ANALYSIS OF INSTRUCTIONAL SUPPORT}

An analysis of learning outcomes showed that there was a significant improvement in knowledge, skills and gaming performance. Comparisons made using the HolmBonferroni method showed that the instructional support effect is greater on the respondent performance compared to the performances and knowledge. Additionally, the effect of instructional support is greater for knowledge than the playing performance. In short, the respondent benefits from the instructional support for each learning outcome, but the effects are much greater on skills and knowledge.

An analysis conducted in accordance with the first classification shows that the instructional support for selection and organization/integration improved the learning outcome. In relation to this, the effect is significantly higher in selection in comparison with organization/integration. The results of the second classification analysis show that the instructional support improves learning in all cases. Other classifications did not prove to be statistically significant. Comparisons made using the Holm-Bonferroni method showed that modality improves learning in relation to collaboration, advice, control, other, reflection, narration, modelling and feedback. Similar to these aforementioned items, personalization raises learning outcomes in relation to collaboration and advice. Other comparisons showed no other significant differences. These authors concluded that instructional support facilitates learning in the selection of important information and improves learning more than the instructional support focused on the organization/integration of new information. Modelling, modality, personalization and feedback are shown to be particularly effective techniques.

In this study, game based learning is deemed to be a complex educational environment. From a cognitive learning perspective, this statement implies that, without instructional support, a respondent could end up using his/her cognitive capacity on non-effective activities (focusing on irrelevant information), which is detrimental to the activities that contribute to learning (reflection). The weighted average effect of quantity may be classified as medial and therefore confirms that the use of instructional support in educational games can improve learning.

These results are consistent with other studies of instructional support in complex educational environments.
In compliance with the multimedia and educational environment, the research also confirms that a welldesigned instructional support enhances learning as it helps the respondent to place an emphasis on the effective use of the cognitive capacity $[14,16,24]$.

Instructional support which helps a respondent to select / choose important information is much more effective than other forms of instructional support that stimulates the organization and integration of new information. This also occurs in the analyses of different types of instructional support such as special modelling (showing information which is important for problem solving and how such information can be used for problem solving), modality (using audio channels for textual descriptions to limit visual search) and feedback (information about whether and why the answer is correct). These techniques are effective in aiding the selection of relevant information. Implementation of such instructional support that encourages respondents to actively participate in the organization and integration of knowledge is very difficult to be carried through. The only exception to this is reflection, which asks respondents to explicitly consider why they took such an action or gave a specific answer. Instructional support that does not use explicit stimulation for organizing and integrating information, such as narration and collaboration is less effective.

In game genres such as adventure games or role-playing games (RPGs), narration plays an important role and can serve as a cognitive framework that gives meaning to the situation and the story [18], but such an element does not increase learning efficiency and can actually create a situation in which a respondent gets distracted from educational materials. Furthermore, the implementation of collaboration does not improve the educational process, although it was intended to serve as a stimulus for students to express their knowledge [20]. Collaboration shows positive results when it is set as a task to respondents requiring from them to enter into discussions with peers or their partners within a group.

All et al. [1] state there is no specific instruction system to effectively implement game based learning. They suggest consultations with experts from relevant fields who have theoretical knowledge and experience of conducting experiments. Several researchers state that without instructional support within an educational computer game, a student is more likely to learn how to play such a game (improve his/her playing performance) than acquire specific knowledge or develop a specific skill [10]. Sitzmann [19] compared the effect of simulation games considering knowledge outcomes (declarative) and skill outcomes (procedural) and found no significant differences. Other authors [25] agreed with this statement but, if educational games are accompanied with instructional support, the results change and the learning outcomes of developed skills were better than of acquiring knowledge, considering that the development of skills is cognitively more demanding than acquiring knowledge. All et al. [1] concluded that research in clearly noticeable laboratory 
conditions should be reduced because their impact on intrinsic motivation is not insignificant. They can be used in certain forms of research but jeopardize the objectivity of the experiment itself. Control groups should receive additional motivation material which would harmonize different groups.

\section{CONCLUSION AND FUTURE WORK}

Game based learning is considered a complex educational environment. From the cognitive point of view on learning, this statement implies that without instructional support, the respondent may use his/her cognitive capacity for non-efficient activities (focusing on irrelevant information), which is detrimental to the activities contributing to learning (reflection). Wouters and van Oostendorp [25] confirmed that the use of instructional support in game based learning can improve learning. For more efficient learning, game based learning with educational games is suggested, where student can benefit from active and problem-oriented learning allowing them to apply their own knowledge to the information and examples from the real world.

Hamari et al. [8] state that the challenge has to be especially analysed during the game and additional instruction design stages. The challenge should be adjusted and should at the same time follow the level of skills and knowledge of the respondent. Also studied was how increased challenges of the computer game increase excitement of the respondents.

The authors suggest, through the empirical evidence of impact and learning outcomes based on game based learning, that a more rigorous quantitative study should be conducted of affective and motivational learning outcomes. The approach that game based learning encourages educational activity in various domains, especially in health care, business and social environments, was accepted. The respondents like the idea of learning through playing, it boosts their motivation and the approach should be studied in more detail. Evidence showing that games contribute to a more efficient learning is not strong enough. Boyle et al. [4] published an amendment to an earlier research which stated that in the last 5 years, the number of works that study the relating area has almost quintupled. From 2009 to 2014, 129 works were discovered that met the criteria of a scientific work. In 2015, the number of works that met the study criteria was 512 , which leads to a conclusion that the topic is of a very high importance. Another fact that demonstrates the relevant nature of the statement is that Boyle's et al. research was partially financed by the European Union Framework Program for Research and Technological Development (FP7).

All et al. [1] conclude that the teacher, administrator or person providing assistance to respondents when they practice game based learning should be removed from the system. Their role should only remain procedural, if so required. A precisely set industrial design should guide a respondent through a repetitive process. Authors claim that this is contrary to research completed so far where the role of the instructor or teacher is very important during the experiment. Authors of this work agree with All et al. who also continue by claiming that future research should isolate a game as much as possible. A detailed description of the implementation and characteristics of the game are as needed as the information on experimental and control groups.

The authors conclude that it would be useful to see several empirical works on the guidelines stated earlier and conclusions on the application of game based learning in higher education. What we suggest is to study efficiency at the level of courses during the entire semester and study the students' motivation. The Croatian educational system is inert, it changes very slowly, and this would be an example of good practice with actual guidelines on how to plan and implement instructional design and measure the knowledge and motivation of candidates who use game based learning as a primary source of knowledge.

\section{REFERENCES}

[1] All, A., Castellar, E. P. N., \& Van Looy, J. (2016). Assessing the effectiveness of digital game-based learning: Best practices. Computers \& Education, 92, 90-103. https://doi.org/10.1016/j.compedu.2015.10.007

[2] Ariffin, M. M., Oxley, A., \& Sulaiman, S. (2014). Evaluating game-based learning effectiveness in higher education. Procedia-Social and Behavioral Sciences, 123, 20-27. https://doi.org/10.1016/j.sbspro.2014.01.1393

[3] Boyle, E., Connolly, T. M., \& Hainey, T. (2011). The role of psychology in understanding the impact of computer games. Entertainment Computing, 2(2), 69-74. https://doi.org/10.1016/j.entcom.2010.12.002

[4] Boyle, E. A., Hainey, T., Connolly, T. M., Gray, G., Earp, J., Ott, M., Lim, T., Ninaus, M., Ribeiro, C., \& Pereira, J. (2016). An update to the systematic literature review of empirical evidence of the impacts and outcomes of computer games and serious games. Computers \& Education, 94, 178-192. https://doi.org/10.1016/j.compedu.2015.11.003

[5] O' Brien, D. (2011). Ch. 1. A taxonomy of educational games. In Gaming and simulations: Concepts, methodologies, tools and applications (pp. 1-23). USA: IGI Global. https://doi.org/10.4018/978-1-60960-195-9.ch101

[6] Connolly, T., Stansfield, M. H., \& Hainey, T. (2008). Development of a general framework for evaluating gamesbased learning. Proceedings of the $2^{\text {nd }}$ European conference on games-based learning. Universitat Oberta de Catalunya Barcelona, Spain, 6-7 October 2016, 105-114.

[7] Garris, R., Ahlers, R., \& Driskell, J. E. (2002). Games, motivation, and learning: A research and practice model. Simulation \& Gaming, 33(4), 441-467. https://doi.org/10.1177/1046878102238607

[8] Hamari, J., Shernoff, D. J., Rowe, E., Coller, B., AsbellClarke, J., \& Edwards, T. (2016). Challenging games help students learn: An empirical study on engagement, flow and immersion in game-based learning. Computers in Human Behavior, 54, 170-179. https://doi.org/10.1016/j.chb.2015.07.045

[9] Hummel, H. G., Van Houcke, J., Nadolski, R. J., Van der Hiele, T., Kurvers, H., \& Löhr, A. (2011). Scripted collaboration in serious gaming for complex learning: Effects of multiple perspectives when acquiring water management skills. British Journal of Educational Technology, 42(6), 1029-1041. https://doi.org/10.1111/j.1467-8535.2010.01122.x 
[10] Ke, F. (2009). A qualitative meta-analysis of computer games as learning tools. Handbook of research on effective electronic gaming in education, 1, 1-32. https://doi.org/10.4018/978-1-59904-808-6.ch001

[11] Malone, T. W. (1981). Toward a theory of intrinsically motivating instruction. Cognitive science, 5(4), 333-369. https://doi.org/10.1207/s15516709cog0504_2

[12] Mayer, R. E. (2002). Multimedia learning. Psychology of learning and motivation, 41, 85-139. https://doi.org/10.1016/S0079-7421(02)80005-6

[13] Mayer, R. E. (2011). Multimedia learning and games. In S. Tobias \& J. D. Fletcher (Eds), Computer games and instruction. Greenwich, CT: Information Age Publishing, 281-305.

[14] Mayer, R. E. \& Moreno, R. (2003). Nine ways to reduce cognitive load in multimedia learning. Educational psychologist, 38(1), 43-52. https://doi.org/10.1207/S15326985EP3801_6

[15] O'Neil, H. F., Wainess, R., \& Baker, E. L. (2005). Classification of learning outcomes: Evidence from the computer games literature. The Cirriculum Journal, 16(4), 455-474. https://doi.org/10.1080/09585170500384529

[16] van Oostendorp, H., Beijersbergen, M. J., \& Solaimani, S. (2008). Conditions for learning from animations. Proceedings of the $8^{\text {th }}$ International Conference of the Learning Sciences, 438-445.

[17] Paas, F., Renkl, A., \& Sweller, J. (2003). Cognitive load theory and instructional design: Recent developments. Educational psychologist, 38(1), 1-4. https://doi.org/10.1207/S15326985EP3801_1

[18] Prensky, M. (2001). Digital game-based learning. Computers in Entertainment (CIE), 1(1), 21-21. https://doi.org/10.1145/950566.950596

[19] Sitzmann, T. (2011). A meta-analytic examination of the instructional effectiveness of computer-based simulation games. Personnel psychology, 64(2), 489-528. https://doi.org/10.1111/j.1744-6570.2011.01190.x

[20] van der Meij, H., Albers, E., \& Leemkuil, H. (2011). Learning from games: Does collaboration help? British Journal of Educational Technology, 42(4), 655-664. https://doi.org/10.1111/j.1467-8535.2010.01067.x

[21] Vogel, J. J., Vogel, D. S., Cannon-Bowers, J., Bowers, C. A., Muse, K., \& Wright, M. (2006). Computer gaming and interactive simulations for learning: A meta-analysis. Journal of Educational Computing Research, 34(3), 229-243. https://doi.org/10.2190/FLHV-K4WA-WPVQ-HOYM

[22] Ucus, S. (2015). Elementary school teachers' views on gamebased learning as a teaching method. Procedia-Social and Behavioral Sciences, 186, 401-409. https://doi.org/10.1016/j.sbspro.2015.04.216

[23] Wang, L. C. \& Chen, M. P. (2010). The effects of game strategy and preference-matching on flow experience and programming performance in game-based learning. Innovations in Education and Teaching International, 47(1), 39-52. https://doi.org/10.1080/14703290903525838

[24] Wouters, P., Van der Spek, E. D., \& Van Oostendorp, H. (2009). Current practices in serious game research: A review from a learning outcomes perspective. In Games-based learning advancements for multi-sensory human computer interfaces: techniques and effective practices. IGI Global, 232-250. https://doi.org/10.4018/978-1-60566-360-9.ch014

[25] Wouters, P., Van Nimwegen, C., Van Oostendorp, H., \& Van Der Spek, E. D. (2013). A meta-analysis of the cognitive and motivational effects of serious games. Journal of educational psychology, 105(2), 249. https://doi.org/10.1037/a0031311
Authors' contacts:

Damir VUSIĆ, PhD, Associate Professor

University North

104. brigade 3, Varaždin, Croatia

dvusic@unin.hr

Andrija BERNIK, PhD, Lecturer

University North

104. brigade 3, Varaždin, Croatia

abernik@unin.hr

Robert GEČEK, Assistant Professor of Art University North

104. brigade 3, Varaždin, Croatia

rgecek@unin.hr 